\title{
Analysis of gene expression in mineralized skeletal tissues by laser capture microdissection and RT-PCR
}

\author{
Yvonne Y Shao, Lai Wang, David G Hicks and R Tracy Ballock \\ Orthopaedic Research Center, Departments of Orthopaedic Surgery and Biomedical Engineering, \\ The Cleveland Clinic Foundation, Cleveland, OH, USA
}

\begin{abstract}
The analysis of gene expression by growth plate chondrocytes in vivo has been hampered by the inherent difficulty in performing in situ hybridization on mineralized tissues. The combination of laser capture microdissection and reverse transcription-polymerase chain reaction (RT-PCR) allows analysis of gene expression by cells selectively removed from histologic sections by laser ablation. In order to apply this method to mineralized tissues, a decalcification process is required. The object of this study was to determine the optimal method for tissue decalcification prior to laser capture microdissection RT-PCR that will preserve integrity of the mRNA population. Acetone, $10 \%$ formalin, and methacarn were evaluated as fixatives, while Surgipath Decalicifier I, 10\% ethylenediaminetetraacetic acid (EDTA), and 20\% EDTA were evaluated as decalcifying reagents. Our results demonstrate that the optimal RNA quality was preserved by a decalcification protocol consisting of $20 \%$ EDTA for decalcification followed by fixation in methacarn, although this method is also associated with a reduction in RNA quantity.
\end{abstract}

Laboratory Investigation (2006) 86, 1089-1095. doi:10.1038/labinvest.3700459; published online 28 August 2006

Keywords: growth plate; cartilage; chondrocyte; laser capture microdissection; mineralization

Longitudinal bone growth occurs at the growth plate which contains several different cell populations. ${ }^{1,2}$ The chondrocytes in each defined region have unique morphological features and patterns of gene expression. The analysis of gene expression in growth plate chondrocytes in vivo has been hampered by the inherent difficulty of performing in situ hybridization on mineralized tissues. This difficulty stems in large part from loss of RNA integrity due to the decalcification process required for histological sectioning.

The recent advent of laser capture microdissection (LMD) combined with the highly sensitive polymerase chain reaction technique now makes it possible to study gene expression in a single population of cells in vivo ${ }^{3-7}$ The quality of RNA resulting from the laser capture technique is heavily dependent on the preparation of the tissue section. Most of the current studies employing the LMD technique have been performed on soft tissue

Correspondence: Dr RT Ballock, MD, Department of Orthopaedic Surgery, A-41, The Cleveland Clinic Foundation, 9500 Euclid Avenue, Cleveland, OH 44195, USA.

E-mail: ballocr@ccf.org

Received 1 February 2006; revised 24 June 2006; accepted 1 July 2006; published online 28 August 2006 sections that were prepared from frozen or paraffinembedded samples. For mineralized tissues, however, a decalcification step is necessary to allow histological sectioning without damage to the tissue specimen in addition to using a proper fixative to preserve tissue morphology.

As both the choice of fixative and decalcifying agent may affect the quality of the RNA in the tissue specimen, the objective of this study was to optimize the fixation and decalcification of mineralized tissue to successfully analyze phenotypically distinct populations of rat growth plate chondrocytes in vivo using laser capture microdissection followed by RT-PCR.

\section{Methods}

All standard chemical and reagents were obtained from Fisher Scientific (Pittsburgh, PA, USA). The SuperScript reverse transcription kit and Trizol were purchased from Invitrogen (Carlsbad, CA, USA). Oligo-deoxynucleoride primers were synthesized by Integrated DNA Technologies (Coralville, IA, USA). Real-time PCR primers, TaqMan Universal PCR Master Mix, and the 18s ribosome RNA internal control were purchased from Applied Biosystems 
(Foster City, CA, USA). A formic acid/formalinbased decalcification solution, Surgipath Decalcifier I, was obtained from Surgipath, Richmond, Illinois, USA.

In order to investigate the effects of tissue fixation and decalcification on LMD-RT-PCR, the results were initially compared to those obtained from frozen sections of neonatal rat femurs, which do not normally require decalcification prior to tissue sectioning. Femurs from 2-day-old Sprague-Dawley (Indianapolis, IN, USA) rats were collected and quickly embedded in OCT and liquid nitrogen and stored at $-80^{\circ} \mathrm{C}$ until used. Frozen sections $(5 \mu \mathrm{m}$ thick) were cut on a cryostat and attached to thin foil membrane slides pretreated with poly-L-lysine to improve tissue adherence.

To determine the effects of tissue fixation and decalcification, femurs from 2-day-old or 6-weekold rats were decalcified in $10 \%$ EDTA or $20 \%$ EDTA in diethyl pyrocarbonate-treated solution for 2 days at $4^{\circ} \mathrm{C}$ using constant agitation. Tissues were then fixed with either acetone or $10 \%$ formalin in PBS, overnight and dehydrated with increasing ethanol concentrations, or were fixed with Methacarn. ${ }^{8}$ Some 2-day-old and 6-week-old specimens were fixed and decalcified simultanenously in Surgipath Decalcifier I overnight. Tissues fixed in freshly prepared Methacarn (methanol 60\%, chloroform $30 \%$, and glacial acetic acid $10 \%$ ) were incubated at $4^{\circ} \mathrm{C}$ for $1 \mathrm{~h}$ followed by dehydration in $100 \%$ ethanol for $1 \mathrm{~h}$. After dehydration, all samples were processed in xylene for $2.5 \mathrm{~h}$ at room temperature with changes every $30 \mathrm{~min}$. All specimens were transferred into hot paraffin $60^{\circ} \mathrm{C}$ for $1 \mathrm{~h}$ for embedding.

All samples (frozen or paraffin-embedded) were cut at $5-7 \mu \mathrm{m}$ thickness and mounted on poly-Llysine treated foil membrane slides. Before being subjected to laser capture microdissection, slides were dewaxed in xylene for $2 \mathrm{~min}$, stained with hematoxylin for $2 \mathrm{~min}$, rinsed with $\mathrm{H}_{2} \mathrm{O}$ once; and stained with eosin for $10 \mathrm{~s}$. Slides were cleared with $95 \%$ ethanol for $30 \mathrm{~s}$, air-dried in a fume hood, and stored at $-80^{\circ} \mathrm{C}$ until used. Laser capture microdissection was performed using a Leica CIR MIC system (Leica, Wetzkar, Germany). Approximately 100 cells per section were dissected by laser ablation and collected in diethyl pyrocarbonate-treated $\mathrm{H}_{2} \mathrm{O}$.

RNA was extracted from LMD samples by the Trizol method (Invitrogen) according to the manufacturer's protocol. The extracted RNA was treated with DNAse I followed by phenol chloroform extraction. The mRNA was reverse transcribed to cDNA (SuperScript, Invitrogen) according to the manufacturer's protocol prior to PCR amplification.

Genes encoding alkaline phosphatase, runt related transcription factor 2 (runx2), bone morphogenetic protein 2 (BMP-2), type II collagen, and osteocalcin were chosen for the gene expression analysis. Conventional PCR conditions were denaturation at $94^{\circ} \mathrm{C}$ for $1 \mathrm{~min}$, annealing at $55^{\circ} \mathrm{C}$ for
$1 \mathrm{~min}$, and extension at $72^{\circ} \mathrm{C}$ for $1 \mathrm{~min}$. for 30 or 42 cycles. The following primers were used for conventional PCR:

alkaline phosphatase

sense TGGCTCTCTCCAAGACGTAC, antisense ATTAGCGATAGGCGATGTCC;

$\operatorname{runx} 2$

sense GCACCATGGTGGAGATCATC, antisense GTCTGTGCCTTCTTGGTTCC;

BMP-2

sense CACCGTGCTCAGCTTCAA, antisense TGCGGAAGTTTTCCCACTCA;

type II collagen

sense TCGCTGGCTTCAAAGGTGAACA, antisense ACCAACTTTGCCTTGAGGACCA; and

osteocalcin

sense AAAGCCTTCATGTCCAAGCAGGAG, antisense TTTCGAGGCAGAGAGAGGGAA.

Negative control PCR reactions were identical to the experimental reactions except that no cDNA template was added. All experiments were repeated at least twice with similar results.

To assess the effect of fixation and decalcification on the quantity of mRNA, TaqMan real time PCR amplification of the parathyroid hormone receptor (PTHR) gene was performed. The assay was carried out on ABI Prism 7700 Sequence Detection System (Applied Biosystems, Foster City, CA, USA). The primers and the probe were designed by Primer Express Software version 2.0, (Applied Biosystems). The primers and probe were

\section{CCATCCTGGCATCTGTTGTG (forward), \\ TTGGTCTCCCGAAGCTTAG (reverse), TCATCCTCTTTATCAACATCATCCGGGTG (FAM probe).}

The ribosomal 18s subunit was used as internal control (Applied Biosystems). The samples were amplified for 40 cycles with denaturation at $95^{\circ} \mathrm{C}$ for $15 \mathrm{~s}$, and annealing/extension at $60^{\circ} \mathrm{C}$ for $1 \mathrm{~min}$. A threshold cycle $\left(C_{\mathrm{t}}\right)$ value was measured that reflected the amount of fluorescence generated from the PCR product of the sample. An absolute quantification (AQ) assay was utilized to determine the quantity of RNA in the unknown sample as described by the manufacturer's protocol. A standard curve was generated using a series of known quantities of RNA (0.8-100 ng) for the RT-PCR template and the $C_{\mathrm{t}}$ value plotted vs the log of the known quantity of RNA. The amount of RNA in the unknown sample was calculated by interpolating 
the value from the standard curve. Results are expressed as mean values \pm s.d.

\section{Results}

Our initial in vivo gene expression experiments on growth place chondrocytes were performed on frozen sections of distal femoral growth cartilage of neonatal rats (Figure 1a). Approximately 100 cells from the proliferative zone and 100 cells from the hypertrophic zone were removed separately by laser capture microdissection. RT-PCR amplification of genes encoding alkaline phosphatase and runx2 was performed on RNA extracted from the microdissected sample and the PCR products visualized on a $1.8 \%$ agarose gel (Figure 1b). The expression of alkaline phosphatase was detected only in hypertrophic zone, while expression of the transcription factor runx2 was detected in hypertrophic zone and as well as in proliferative zone, as previously described by Tchetina et al. ${ }^{9}$

To determine the effect of tissue fixation on LMDRT-PCR, three different fixatives (acetone, 10\% formalin, and methacarn) were tested on neonatal rat distal femoral growth cartilage and compared to the unfixed frozen tissue sections described above. Figure 2 demonstrates that tissues fixed with

a
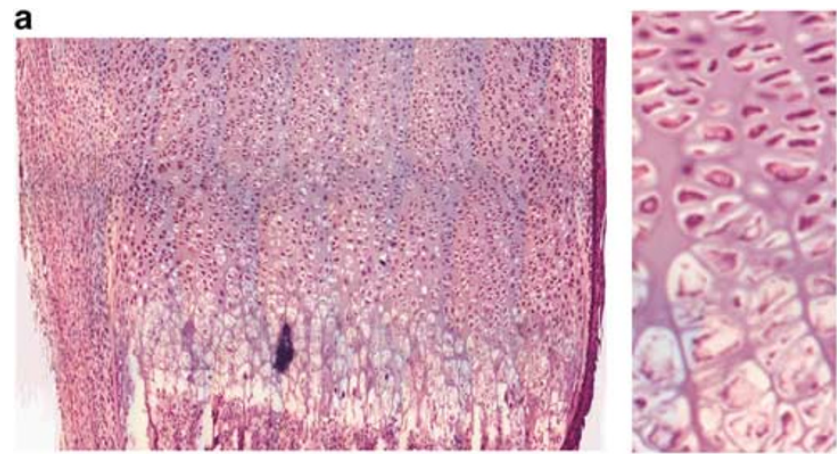

b

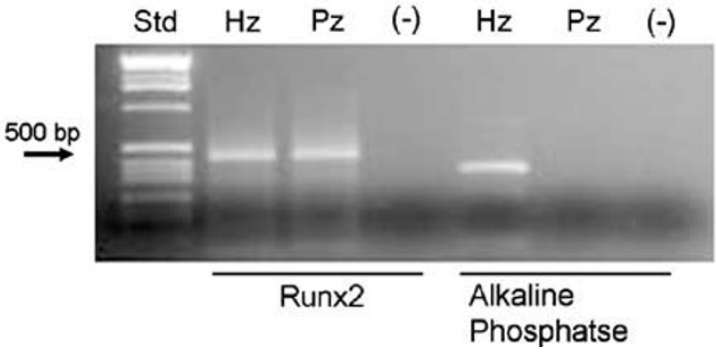

Figure 1 (a) Histologic appearance of the neonatal rat distal femur. Fresh frozen tissue was embedded in OCT, and sectioned at $5 \mu \mathrm{m}$ thickness prior to laser capture microdissection. The left panel shows the appearance of growth plate tissue from a two day-old neonatal rat femur, while the right panel shows more detailed cellular structure. (b) RT-PCR of mRNA extracted from $\sim 100$ cells from the hypertrophic zone (HZ) or proliferative zone (PZ) cells removed by laser capture microdissection. Negative control ( $(-)$ had no cDNA template added. PCR product size was $395 \mathrm{bp}$ for runx2 and $342 \mathrm{bp}$ for alkaline phosphatase. acetone or $10 \%$ formalin failed to result in successful amplification, however, methacarn-fixed tissue yielded a successful RT-PCR product.

To determine the effect of tissue decalcification on LMD-RT-PCR, 6-week-old rat femurs were either decalcified and fixed simultaneously in Surgipath Decalcifier I solution overnight, or decalcifed for two days in either 10 or $20 \%$ EDTA at $4{ }^{\circ} \mathrm{C}$ and then fixed in methacarn. All samples were then embedded in paraffin prior to LMD-RT-PCR. To determine if the order of the decalcification-fixation sequence was critical, some specimens were initially fixed in methacarn and subsequently decalcified in 20\% EDTA for 2 days.

Successful LMD-RT-PCR was only observed from specimens decalcified in 10 or $20 \%$ EDTA followed by fixation in methacarn (Figure 3a). No product was visualized from specimens fixed and decalcified in Surgipath Decalcifier I, or from specimens

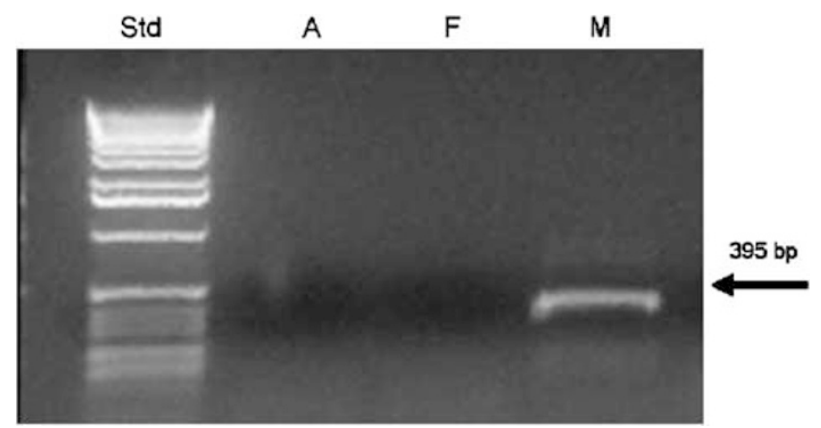

Figure 2 Rat (2-day-old) femurs were fixed by acetone (A), formalin $(\mathrm{F})$, or methacarn $(\mathrm{M})$ prior to paraffin embedding. RTPCR of mRNA extracted from equal numbers of cells. PCR product size for runx2 was $395 \mathrm{bp}$.

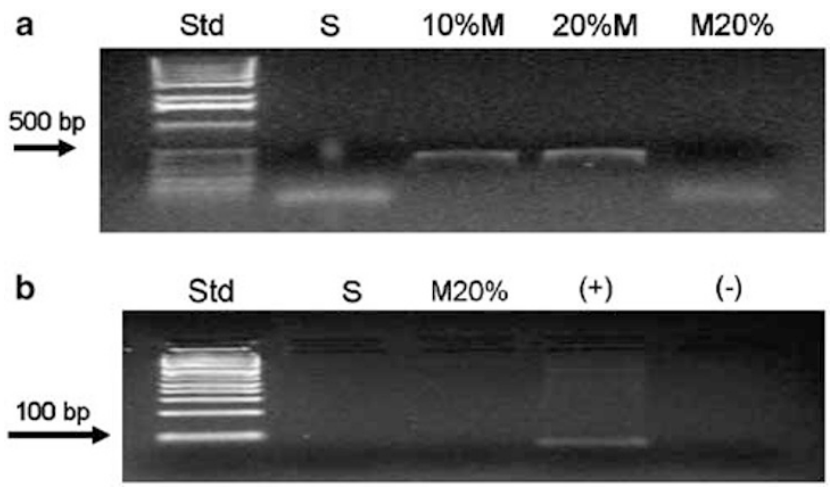

Figure 3 (a) Rat (6-week-old) femurs were decalcified and fixed simultaneously in Surgipath Decalcifier I (S), or decalcified in either $10 \%$ EDTA $(10 \% \mathrm{M})$ or $20 \%$ EDTA $(20 \% \mathrm{M})$, then fixed in methacarn, or fixed in methacarn then decalcified with $20 \%$ EDTA (M20\%). All samples were embedded in paraffin. RT-PCR was performed on RNA extracted from equal number cells. PCR product size for runx 2 was $395 \mathrm{bp}$. (b) RT-PCR using a shorter target of $69 \mathrm{bp}$ of the rat BMP-2 gene. The PCR reaction was performed for 42 cycles. Positive control $(+)$; Negative control (-). 

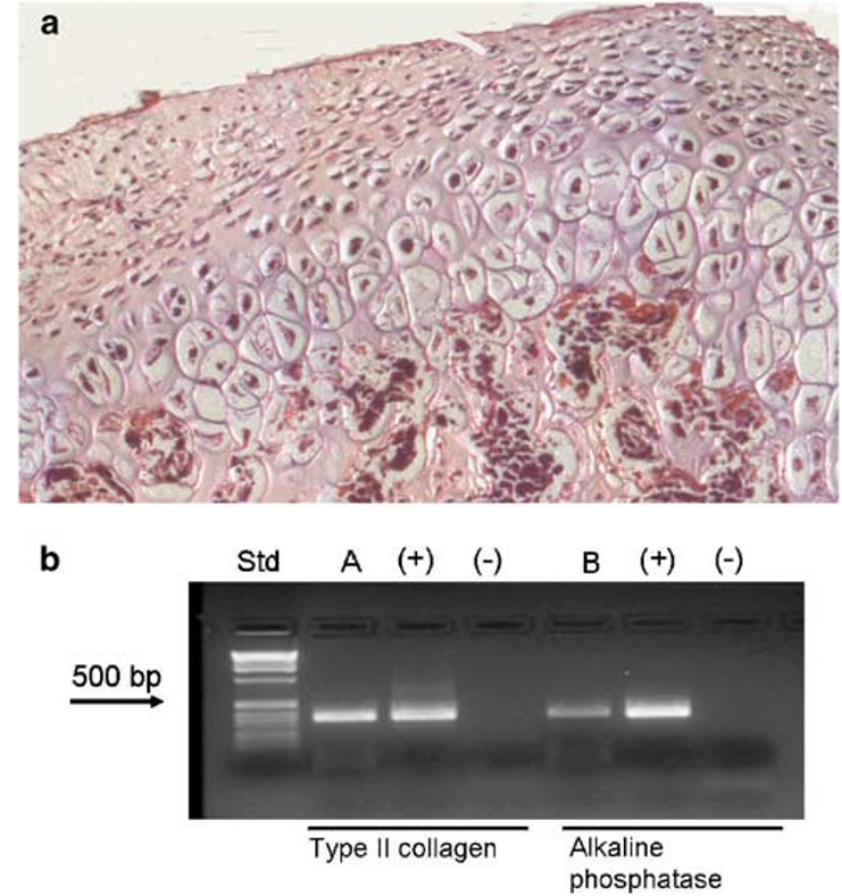

Figure 4 (a) Histologic appearance of articular chondrocytes from the six week-old rat femur. (b) RT-PCR analysis of articular chondrocytes from laser capture microdissection samples; $(+)=$ positive control; $(-)=$ negative control; PCR product size is $349 \mathrm{bp}$ for type II collagen, and $342 \mathrm{bp}$ for alkaline phosphatase.

initially fixed with methacarn prior to decalcification in $20 \%$ EDTA. In order to determine if these RT-PCR reactions failed because of degradation of the mRNA into fragments that were too short for amplification of the original PCR products, the specimens were retested using a shorter RT-PCR target. Figure $3 \mathrm{~b}$ demonstrates that even with 42 cycles of PCR, no product was visualized from the specimens treated with Surgipath or methacarn fixation prior to decalcification. To determine if LMD-RT-PCR was affected by shelf-life of the samples, a specimen decalcified in EDTA and fixed in methacarn was tested 1 year after original tissue processing and storage at $-80^{\circ} \mathrm{C}$. This sample also resulted in successful amplification of the RT-PCR product (data not shown).

In order to determine if gene expression could be detected in skeletal tissues other than growth plate cartilage, laser capture microdissection was also performed on articular chondrocytes (Figure 4a). Expression of the cartilage-specific type II collagen gene was detected in articular chondrocytes but not expression of osteocalcin (Figure $4 \mathrm{~b}$ ).

We next examined the effect of tissue decalcification on RNA integrity by gel electrophoresis and ethidium bromide staining. The total RNA from neonatal rat distal femoral growth cartilage was collected from either fresh frozen tissue and embedded in OCT, or fixed in methacarn immediately
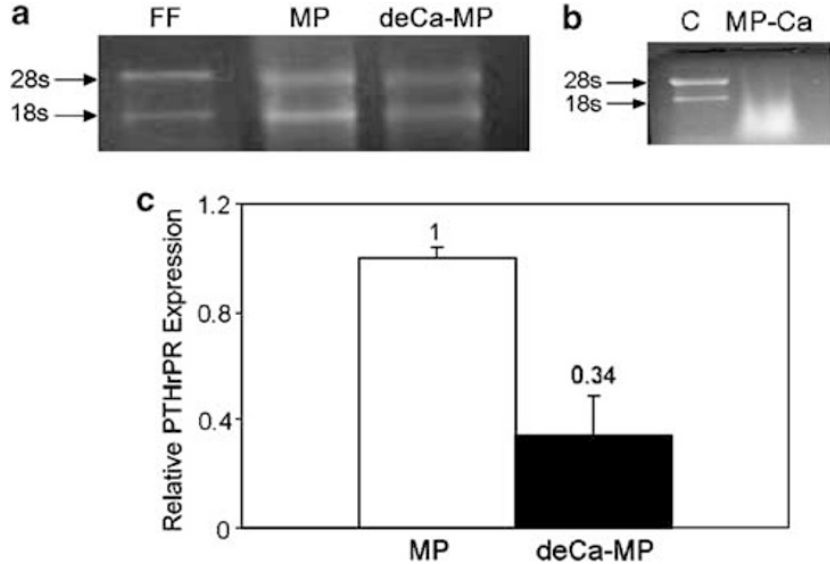

Figure 5 (a) Total RNA extracted from neonatal rat distal femoral growth cartilage tissue sections. Sections were prepared from fresh frozen tissue (FF), methacarn-fixed, paraffin-embedded tissue (MP), or tissue decalcified prior to methacarn fixation (deCa-MP). (b) RNA was prepared from growth plate cells cell as a control (c), or from tissue fixed in methacarn first followed by decalcification for two days (MP-Ca). Arrows indicate the 28 and 18s ribosomal RNA location. (c) Total RNA was extracted from equal numbers of cells, and quantitative real time RT-PCR performed on methacarn-fixed, paraffin-embedded tissue without decalcification (MP) or with decalcification (deCa-MP). Expression of the PTH/PTHrP receptor gene was normalized to the nondecalcified samples.

or after decalcification in $20 \%$ EDTA solution at $4^{\circ} \mathrm{C}$ for 2 days prior to paraffin embedding. The quality of the RNA extracted from fresh frozen tissues or tissues fixed by methacarn and embedded in paraffin with or without decalcification were comparable (Figure 5a), while RNA prepared from the tissue that was fixed in methacarn first followed by 2 days of decalcification was degraded (Figure 5b).

To determine the effect of tissue decalcification on RNA quantity, RNA extracted from paraffinembedded samples with or without decalcification was analyzed by quantitative real-time RT-PCR. Equal numbers of cells were microdissected in both cases. Although all samples resulted in successful amplification, the decalcified sample yielded $70 \%$ less PCR product compared to the undecalcified sample (Figure 5c). The appearance of the decalcified, methacarn-fixed, paraffin-embedded growth plate before and after laser capture microdissection is illustrated in Figure 6.

Growth plate cells were also dissected from decalcified tissue using standard areas of dissection prior to RNA extraction and real-time RT-PCR. Multiples of the standard areas $(2 \times$ and $4 \times)$ were then compared to ascertain whether the PCR product from the $4 \times$ area would be twice as great as from the $2 \times$ area as predicted. The results indicate that gene expression was indeed directly proportional to the number (area) of cells dissected within a precision of $15 \%$ of the expected value (Figure 7a and b). 

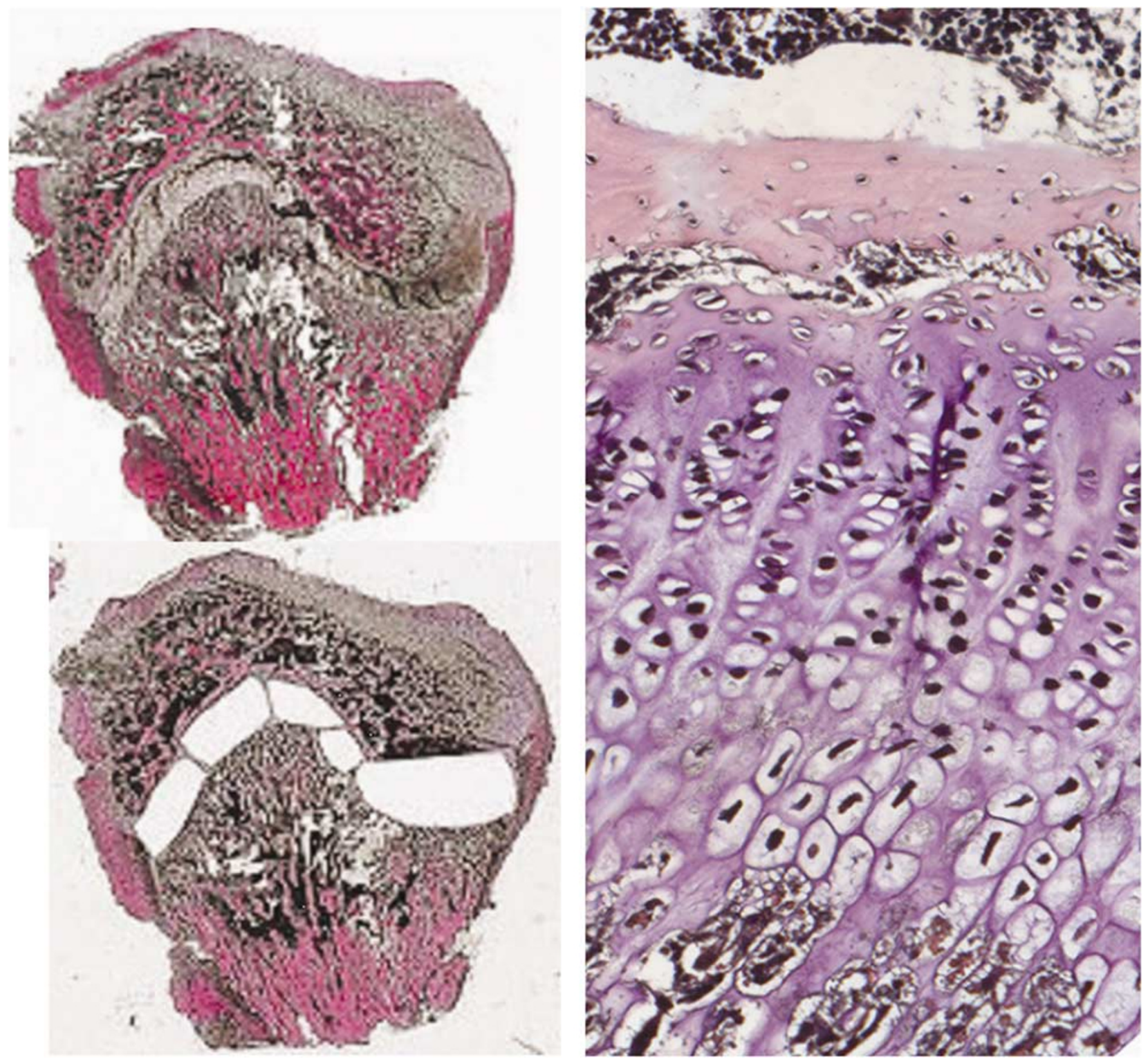

Figure 6 Histologic appearance of six week-old rat femur before (upper left panel), and after (lower left panel) laser capture microdissection. Higher power detail of the growth plate chondrocytes is illustrated in the right-panel. The tissue was decalcified in $20 \%$ EDTA, fixed in methacarn, and embedded in paraffin. The tissue was cut to a thickness of $7 \mu \mathrm{m}$ and stained with hematoxylin and eosin for laser capture microdissection.

\section{Discussion}

The technique of laser capture microdissection is a powerful tool for analysis of cell function in vivo, and has been performed in conjunction with DNA microarrays, ${ }^{10}$ ribonuclease protection assays; ${ }^{11}$ and RT-PCR for studies of gene expression, and in conjunction with two-dimensional polyacrylamide gel electrophoresis, ${ }^{12}$ chemiluminescent immunoassays, ${ }^{13}$ 2D-gel electrophoresis, ${ }^{14}$ and immunoblotting for analysis of proteins. ${ }^{15}$ All of these previously reported studies were performed on soft tissues, most likely because of the difficulties inherent in studying mineralized tissues due to the need for tissue decalcification. Decalcification with acidic solutions in particular predictably results in hydrolysis and degradation of nucleic acids, which results in short RNA and DNA fragments that are often unsuitable for subsequent analysis by RT-PCR or in situ hybridization. An exception to this is a study of neonatal mouse cartilage by Landis et al. ${ }^{16,17}$

Although fresh frozen undecalcified tissue can be sectioned by modifying the cryochamber and using a disposable blade made from special high-grade tungsten carbide, ${ }^{16}$ decalcification is often required for optimal histologic detail. Several different decalcifying reagents have been evaluated for compatibility with extraction of DNA for $\mathrm{PCR}^{18-20}$ or preservation of RNA for in situ hybridization. ${ }^{21}$ The common conclusion of these studies is that 
1094
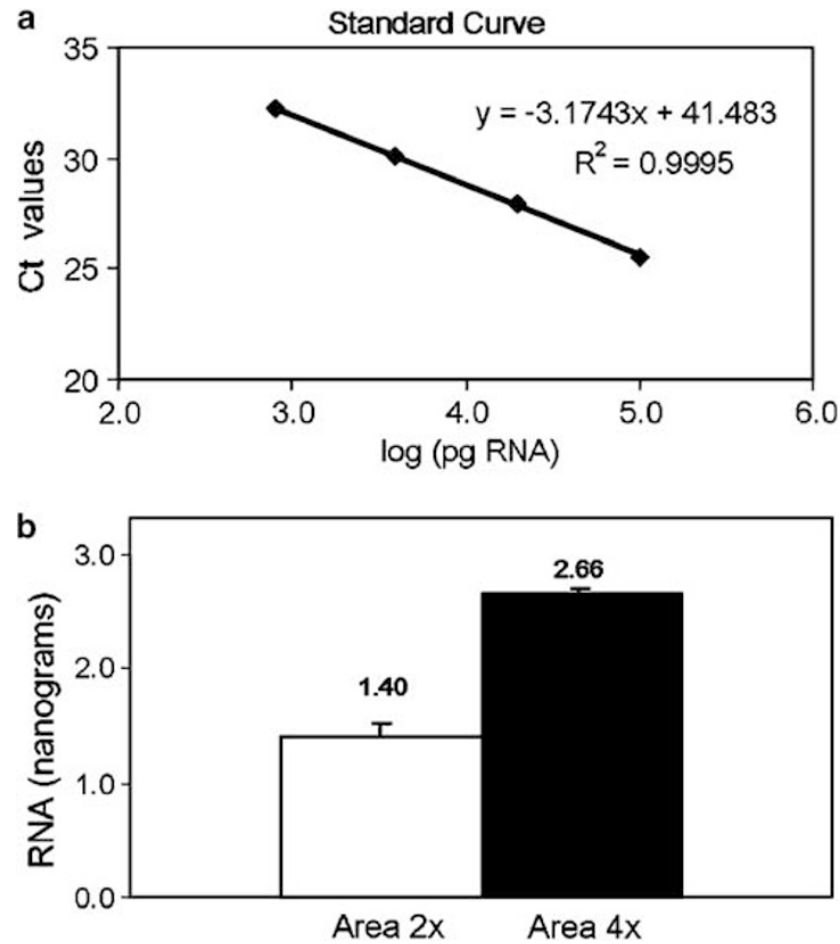

Figure 7 Absolute RNA quantification assay. (a) The standard curve was generated from RT-PCR from $0.8,4,20$ and $100 \mathrm{ng}$ of RNA. (b) RNA was extracted from multiples of a standardized area $(2 \times$ and $4 \times)$ and quantitative real-time RT-PCR performed.

prolonged decalcification with EDTA concentrations up to $10 \%$ for 6 days provided the most optimal preservation of nucleic acids.

To retain high-quality RNA, flash freezing tissue in liquid nitrogen is often recommended, but may be impractical outside of a research facility, and does not provide the degree of morphologic cellular detail necessary for accurate histological evaluation, particularly in complex tissues composed of multiple different cell types. Paraffin embedding of fixed tissue not only provides excellent histologic detail, but also has the advantage of easy handling and storage. Various fixatives and tissue handling protocols have, therefore, been investigated for their compatibility with nucleic acids. ${ }^{22-24}$ Buffered formalin solution is the most commonly used tissue fixative, but results in very poor recovery of RNA due to formation of crosslinks between nucleic acids and proteins, ${ }^{25}$ as well as formalin-induced chemical modification of RNA. ${ }^{26}$ Fixation with ethanol and methanol-based solutions results in less chemical modification and higher yields of extraction of nucleic acids. Methacarn, a methanol-based fixative, was first reported as compatible with RNA extraction by Puchtler, ${ }^{8}$ and has been recommended for analysis of genomic DNA as well. ${ }^{27}$ Recently methacarn fixation was shown to result in the highest integrity and amount of RNA compared with other fixatives. ${ }^{28}$

In this study we have shown that that laser capture microdissection combined with RT-PCR is a very sensitive and powerful tool. The LMD-RTPCR technique allows removal of phenotypically distinct populations of chondrocytes from growth plate cartilage, with as few as 100 cells required to analyze gene expression. We have also demonstrated that decalcification of mineralized tissue with high concentrations of EDTA $(20 \%)$ for two days followed by fixation in methacarn results in optimal RNA preservation for RT-PCR studies. It is interesting to note when the order of the decalcification and fixation steps were reversed, no RT-PCR product could be amplified. We speculate that this may due to an increased length of the time required for complete fixation of mineralized tissue compared to decalcified tissue. In addition, tissue samples prepared in the manner described above can be stored for upward of a year, facilitating follow-up study at a later time using these same tissue blocks.

The conclusions of this study are that choice of fixative and decalcifying agent for the study of mineralized tissues is critical to the success of the LMD-RT-PCR technique, and that decalcification in EDTA followed by fixation in methacarn results in optimal preservation of RNA for RT-PCR studies of gene expression. These findings should facilitate detailed morphologic, spatial and topographic studies of gene expression in mineralized skeletal tissues utilizing the LMD-RT-PCR technique.

\section{References}

1 Ballock RT, O’Keefe RJ. Physiology and pathophysiology of the growth plate. Birth Defects Res C Embryo Today 2003;69:123-143.

2 Kronenberg HM. Developmental regulation of the growth plate. Nature 2003;423:332-336.

3 Kamme F, Zhu J, Luo L, et al. Single-cell laser-capture microdissection and RNA amplification. Methods Mol Med 2004;99:215-223.

4 Ketterer K, Rao S, Friess H, et al. Reverse transcriptionPCR analysis of laser-captured cells points to potential paracrine and autocrine actions of neurotrophins in pancreatic cancer. Clin Cancer Res 2003;9:5127-5136.

5 Mojsilovic-Petrovic J, Nesic M, Pen A, et al. Development of rapid staining protocols for laser-capture microdissection of brain vessels from human and rat coupled to gene expression analyses. J Neurosci Methods 2004;133:39-48.

6 Cheng L, MacLennan GT, Zhang S, et al. Laser capture microdissection analysis reveals frequent allelic losses in papillary urothelial neoplasm of low malignant potential of the urinary bladder. Cancer 2004;101: 183-188.

7 Jin L, Majerus J, Oliveira A, et al. Detection of fusion gene transcripts in fresh-frozen and formalin-fixed paraffin-embedded tissue sections of soft-tissue sarcomas after laser capture microdissection and rt-PCR. Diagn Mol Pathol 2003;12:224-230.

8 Puchtler H, Waldrop FS, Meloan SN, et al. Methacarn (methanol-Carnoy) fixation. Practical and theoretical considerations. Histochemie 1970;21:97-116. 
9 Tchetina E, Mwale F, Poole AR. Distinct phases of coordinated early and late gene expression in growth plate chondrocytes in relationship to cell proliferation, matrix assembly, remodeling, and cell differentiation. J Bone Miner Res 2003;18:844-851.

10 Cristobal R, Wackym PA, Cioffi JA, et al. Assessment of differential gene expression in vestibular epithelial cell types using microarray analysis. Brain Res Mol Brain Res 2005;133:19-36.

11 Shimamura M, Garcia JM, Prough DS, et al. Laser capture microdissection and analysis of amplified antisense RNA from distinct cell populations of the young and aged rat brain: effect of traumatic brain injury on hippocampal gene expression. Brain Res Mol Brain Res 2004;122:47-61.

12 Ornstein DK, Gillespie JW, Paweletz CP, et al. Proteomic analysis of laser capture microdissected human prostate cancer and in vitro prostate cell lines. Electrophoresis 2000;21:2235-2242.

13 Simone NL, Remaley AT, Charboneau L, et al. Sensitive immunoassay of tissue cell proteins procured by laser capture microdissection. Am J Pathol 2000;156:445-452.

14 De Souza AI, McGregor E, Dunn MJ, et al. Preparation of human heart for laser microdissection and proteomics. Proteomics 2004;4:578-586.

15 Martinet W, Abbeloos V, Van Acker N, et al. Western blot analysis of a limited number of cells: a valuable adjunct to proteome analysis of paraffin waxembedded, alcohol-fixed tissue after laser capture microdissection. J Pathol 2004;202:382-388.

16 Landis WJ, Jacquet R, Hillyer J, et al. Analysis of osteopontin in mouse growth plate cartilage by application of laser capture microdissection and RTPCR. Connect Tissue Res 2003;44(Suppl 1):28-32.

17 Jacquet R, Hillyer J, Landis WJ. Analysis of connective tissues by laser capture microdissection and reverse transcriptase-polymerase chain reaction. Anal Biochem 2005;337:22-34.

18 Moore JL, Aros M, Steudel KG, et al. Fixation and decalcification of adult zebrafish for histological, immunocytochemical, and genotypic analysis. Biotechniques 2002;32:296-298.
19 Wickham CL, Boyce M, Joyner MV, et al. Amplification of PCR products in excess of 600 base pairs using DNA extracted from decalcified, paraffin wax embedded bone marrow trephine biopsies. Mol Pathol 2000; 53:19-23.

20 Yamamoto-Fukud T, Shibata Y, Hishikawa Y, et al. Effects of various decalcification protocols on detection of DNA strand breaks by terminal dUTP nick end labelling. Histochem J 2000;32:697-702.

21 Shibata Y, Fujita S, Takahashi H, et al. Assessment of decalcifying protocols for detection of specific RNA by non-radioactive in situ hybridization in calcified tissues. Histochem Cell Biol 2000;113: 153-159.

22 Goldsworthy SM, Stockton PS, Trempus CS, et al. Effects of fixation on RNA extraction and amplification from laser capture microdissected tissue. Mol Carcinog 1999;25:86-91.

23 Gillespie JW, Best CJ, Bichsel VE, et al. Evaluation of non-formalin tissue fixation for molecular profiling studies. Am J Pathol 2002;160:449-457.

24 Vincek V, Nassiri M, Block N, et al. Methodology for Preservation of High Molecular-Weight RNA in Paraffin-Embedded Tissue: Application for LaserCapture Microdissection. Diagn Mol Pathol 2005;14: 127-133.

25 Park YN, Abe K, Li H, et al. Detection of hepatitis C virus RNA using ligation-dependent polymerase chain reaction in formalin-fixed, paraffin-embedded liver tissues. Am J Pathol 1996;149:1485-1491.

26 Masuda N, Ohnishi T, Kawamoto S, et al. Analysis of chemical modification of RNA from formalin-fixed samples and optimization of molecular biology applications for such samples. Nucleic Acids Res 1999; 27:4436-4443.

27 Uneyama C, Shibutani M, Masutomi N, et al. Methacarn fixation for genomic DNA analysis in microdissected, paraffin-embedded tissue specimens. J Histochem Cytochem 2002;50:1237-1245.

$28 \mathrm{Kim}$ JO, Kim HN, Hwang MH, et al. Differential gene expression analysis using paraffin-embedded tissues after laser microdissection. J Cell Biochem 2003;90: 998-1006. 